\section{Commentary: Repairing the candy cane}

\author{
Benny Weksler, MBA, MD
}

Anastomotic complications after Roux-en-Y esophagojejunostomy are relatively common, occurring in nearly $6 \%$ of all patients, ${ }^{1}$ but they may be as high as $10 \%$ in reoperative cases. ${ }^{2}$ The incidence of late complications, including strictures and other functional syndromes, is not well established. One of those late complications is the "candy cane" syndrome. Patients experience abdominal pain, nausea, and emesis and have a dilated blind afferent loop at the esophagojejunal anastomosis. The anastomosis is often herniated into the chest. ${ }^{3}$ Resection of the blind afferent limb (the "candy cane"), usually through a laparoscopic approach, is curative. Aryaie and colleagues ${ }^{3}$ reported on 19 patients with "candy cane" syndrome after gastric bypass. The majority (18 patients) underwent laparoscopic resection of the afferent limb, and 1 patient had an open resection. Postoperatively, 18 patients $(94 \%)$ had complete resolution of their symptoms.

In the present issue of the JTCVS Techniques, Cobb and $\mathrm{Banki}^{4}$ report on a complex patient who underwent multiple abdominal surgeries, including a Roux-en-Y gastric bypass after a failed gastric banding. The gastric bypass was complicated with abdominal sepsis. The patient's anastomosis herniated into the chest, and she was symptomatic. Approximately 2 years after the gastric bypass, a laparoscopic revision was attempted but aborted due to extensive adhesions. She was referred to thoracic surgery with dysphagia, regurgitation, and significant weight loss.

From the Department of Thoracic and Cardiovascular Surgery, Allegheny General Hospital, Pittsburgh, Pa.

Disclosures: Dr Weksler is a proctor for Intuitive Surgery and Speaker for AstraZeneca.

The Journal policy requires editors and reviewers to disclose conflicts of interest and to decline handling or reviewing manuscripts for which they may have a conflict of interest. The editors and reviewers of this article have no conflicts of interest.

Received for publication Jan 25, 2020; revisions received Jan 25, 2020; accepted for publication Feb 2, 2020; available ahead of print Feb 19, 2020.

Address for reprints: Benny Weksler, MBA, MD, Department of Thoracic and Cardiovascular Surgery, Allegheny General Hospital, Pittsburgh, PA 15212 (E-mail: benny.weksler@ahn.org).

JTCVS Techniques 2020;2:156-7

2666-2507

Copyright $@ 2020$ The Authors. Published by Elsevier Inc. on behalf of The American Association for Thoracic Surgery. This is an open access article under the CC BY-NCND license (http://creativecommons.org/licenses/by-nc-nd/4.0/).

https://doi.org/10.1016/j.xjtc.2020.02.001

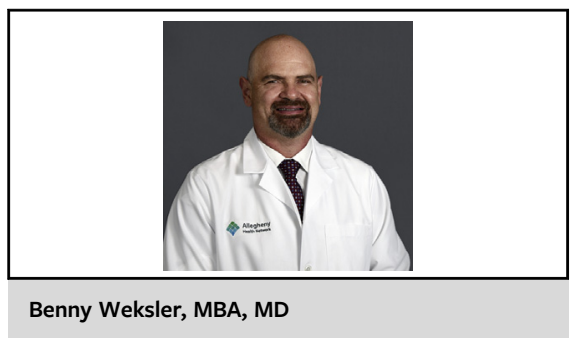

CENTRAL MESSAGE

A redundant afferent limb after

gastric bypass causes the "candy

cane" syndrome. Resection of

the redundant bowel is curative.

A short afferent limb will prevent

the "candy cane" syndrome.

Preoperative testing revealed a herniated anastomosis with a redundant afferent limb, characterizing a candy cane limb. The authors then performed a thoracoscopy and a resection of the candy cane afferent limb with a resolution of the symptoms.

Thoracic surgeons are often in a privileged position of being able to access the esophagus from either the chest or the abdomen. In the case described by Cobb and Banki, a hostile abdomen precluded a more straightforward laparoscopic approach. The authors decided on a novel thoracoscopic approach to resect the candy cane limb. Their approach demonstrates ingenuity and innovative thinking when faced with a challenging situation. All surgeons facing a similar problem should consider a transthoracic approach. Robotic technology may facilitate a transthoracic procedure that took nearly 4 hours, and it may offer advantages when working in small spaces and on the esophagus from the left side. Another minimally invasive approach that should be considered in these difficult cases is the endoluminal obliteration of the afferent loop using the OverStitch Endoscopic Suturing System (Apollo Endosurgery, Austin, Tex). ${ }^{5}$ In any case, an ounce of prevention is worth a pound of cure. The afferent limb in Roux-en-Y gastric bypass needs to be short to prevent a dilated candy cane afferent limb and associated symptoms.

\section{References}

1. Okabe H, Tsunoda S, Tanaka E, Hisamori S, Kawada H, Sakai Y. Is laparoscopic total gastrectomy a safe operation? A review of various anastomotic techniques and their outcomes. Surg Today. 2015;45:549-58. 
2. Awais O, Luketich JD, Tam J, Irshad K, Schuchert MJ, Landreneau RJ, et al. Rouxen-Y near esophagojejunostomy for intractable gastroesophageal reflux after antireflux surgery. Ann Thorac Surg. 2008;85:1954-9; discussion 1959-61.

3. Aryaie AH, Fayezizadeh M, Wen Y, Alshehri M, Abbas M, Khaitan L. "Candy cane syndrome": an underappreciated cause of abdominal pain and nausea after Roux-en-Y gastric bypass surgery. Surg Obes Relat Dis. 2017;13:1501-5.
4. Cobb T, Banki F. Thoracoscopic revision of a herniated Roux-en-Y esophagojejunostomy for treatment of "candy cane syndrome" J Thorac Cardiovasc Surg Tech. 2020;2:153-5.

5. Granata A, Cicchese N, Amata M, De Monte L, Bertani A, Ligresti D, et al "Candy cane" syndrome: a report of a mini-invasive endoscopic treatment using OverStitch, a novel endoluminal suturing system. Endoscopy. 2019;51:E16-7. 